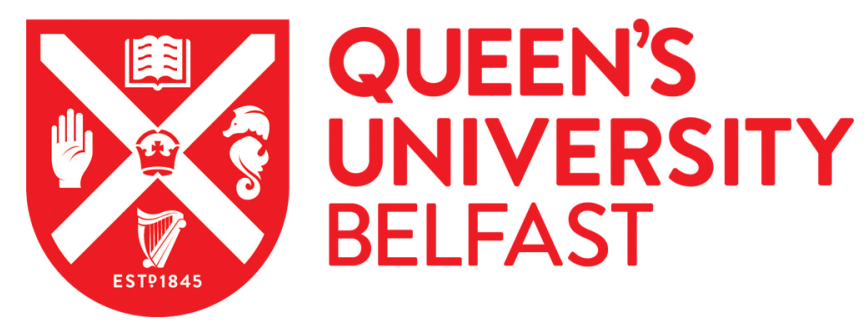

\title{
Making Social Work Count: A Curriculum Innovation to Teach Quantitative Research Methods and Statistical Analysis to Undergraduate Social Work Students in the United Kingdom
}

Devaney, J., Teater, B., Roy, J., Carpenter, J., Forrester, D., \& Scourfield, J. (2017). Making Social Work Count: A Curriculum Innovation to Teach Quantitative Research Methods and Statistical Analysis to Undergraduate Social Work Students in the United Kingdom. Journal of Teaching in Social Work, 1-16.

https://doi.org/10.1080/08841233.2017.1381216

\section{Published in:}

Journal of Teaching in Social Work

Document Version:

Peer reviewed version

Queen's University Belfast - Research Portal:

Link to publication record in Queen's University Belfast Research Portal

Publisher rights

(c) 2017 Taylor \& Francis.

This work is made available online in accordance with the publisher's policies. Please refer to any applicable terms of use of the publisher.

\section{General rights}

Copyright for the publications made accessible via the Queen's University Belfast Research Portal is retained by the author(s) and / or other copyright owners and it is a condition of accessing these publications that users recognise and abide by the legal requirements associated with these rights.

Take down policy

The Research Portal is Queen's institutional repository that provides access to Queen's research output. Every effort has been made to ensure that content in the Research Portal does not infringe any person's rights, or applicable UK laws. If you discover content in the

Research Portal that you believe breaches copyright or violates any law, please contact openaccess@qub.ac.uk. 
Running head: MAKING SOCIAL WORK COUNT

Making Social Work Count: A Curriculum Innovation to Teach Quantitative Research Methods and Statistical Analysis to Undergraduate Social Work Students in the United Kingdom 


\begin{abstract}
Students in the United Kingdom (UK) are found to lack knowledge and skills in quantitative research methods. In order to address this gap, a quantitative research method and statistical analysis curriculum comprised of 10 individual lessons was developed, piloted, and evaluated at two universities in the UK. The evaluation found BSW students' ( $N=81)$ self-efficacy to improve significantly from pre- to post-test, but statistical knowledge improved only slightly and was not statistically significantly. The findings point to recommendations for social work educators in the UK and beyond to consider when integrating the 10-input quantitative method curriculum and when teaching research methods and statistics to social work students.
\end{abstract}

Keywords: BSW students; teaching research; curriculum development; quantitative methods; statistics; research self-efficacy 
Making Social Work Count: A Curriculum Innovation to Teach Quantitative Research Methods and Statistical Analysis to Undergraduate Social Work Students in the United Kingdom

There is a growing emphasis for social work students and practitioners to be "researchminded” where they are able to understand the process of research and use research to inform their practice (Author, year; MacIntyre \& Paul, 2013). Within the United Kingdom (UK), the Quality Assurance Agency (QAA), which sets out expectations and standards for receiving a degree in specific disciplines, calls for students in undergraduate social work education to gain “...the acquisition of research skills in order to build a repertoire of research-based practice,” which includes knowledge of statistical techniques and the use of research to "collect, analyse and interpret relevant information” (QAA, 2008, p. 10; 17). Despite the desire for social work students and future practitioners to be research-minded, there are some identified obstacles to this development within the UK. The most noted obstacle is the historical lack of attention to research methods in social work education and training, (Orme \& Powell, 2008), particularly in relation to quantitative research methods and statistical analysis (Author, year; Sharland, 2009).

This paper reports on an Economic and Social Research Council (ESRC)-funded project to develop and pilot a new quantitative research methods and statistical analysis curriculum for use by social work academics in UK universities teaching undergraduate social work students. The aim of the curriculum, referred to throughout as "quantitative methods curriculum," is to increase students' confidence and basic understanding of quantitative research methods and statistical analysis as applied to social work research.

\section{Background and Context}

\section{Teaching Research in Social Work Education}


Although the teaching of research in social work education is clearly stated within the QAA's expectations and standards for social work education in the UK, there is variation across social work programs as to the extent to which it is covered or embedded within the curriculum. A UK-wide audit of research methods teaching (Orme, Sharland, Manthorpe, Fook, \& Powell, 2008) found that the lack of training and expertise in quantitative methods of social work academics led to an imbalance in terms of the range of methods and analytical approaches covered in research methods classes with less emphasis on quantitative methods, use of computers, or statistical packages. Additionally, the lack of expertise resulted in academics from other disciplines, such as nursing or sociology, teaching quantitatively focused sessions in research methods classes. Such factors served as barriers to the teaching of research methods and quantitative methods and statistics in particular (Orme et al., 2008; Sharland, 2009).

The limited extent of teaching in quantitative methods is not unique to social work, but has been identified as an area for development across the social sciences in the UK more generally (ESRC, 2015). And, as we discuss below, there is documentation for a need to build quantitative methods skills of social work students in the United States (US) and Canada.

\section{Barriers and Facilitators to Teaching Quantitative Methods in Social Work}

Social work students are often labeled as being "research reluctant," anxious or ambivalent toward research, particularly in relation to quantitative methods, and are viewed as lacking confidence in their research abilities (Epstein, 1987). Such attributes can all serve as barriers to teaching quantitative methods; both for students in receiving and processing the information and for lecturers in delivering the material. Yet, there are problems with labeling students as research reluctant, as previous research in the US has suggested. Whereas Green, Bretzin, Leininger, and Stauffer (2001) found social work students at Masters level were more 
anxious and less research-oriented when compared to psychology and business students, Secret, Ford, and Rompf (2003) found the predictors of attitudes towards research are not so simplistic and universal. They found that particular student attributes were found to explain research reluctance and attitudes, for example, women and students with less statistical knowledge held more negative attitudes. More positive attitudes were found to be amongst older students and those who had higher levels of social work empowerment as measured by the Social Work Empowerment Scale (SWES), which measures collective identity, knowledge and skills, selfconcept, critical awareness, and propensity to act. Finally, US and Canadian studies have found anxiety and research reluctance to vary based on the extent to which students find the relevance of research as useful to their social work practice. Bolin, Lee, GlenMaye, and Yoon (2011) found that students who believed research to be useful and important had higher interest in, and less anxiety toward research. High research anxiety was linked to a lack of knowledge, understanding and experience with research (Morgenshtern, Freymond, Agyapong, \& Greeson, 2011, p. 561).

Confidence has also been found to vary based on the extent to which the students are able to participate and practice in research-related activities. By incorporating an online statistics lab in a research methods course, Elliott, Choi, and Friedline (2013) in the US found an increase in students' positive attitudes towards statistics and an increased confidence, particularly in regard to their ability to read and understand scholarly articles. Several factors have been found to facilitate a reduction in anxiety, an increase in confidence, and more positive attitudes of students towards research. For example, a research-friendly and supportive environment where students are able to see the relevance of research to social work practice, are able to practice applying the concepts to "real-life like" situations (e.g., case studies), and where the instructors enthusiastically bring in their own research are identified as key ingredients to teaching research 
methods to social work students (Bolin et al., 2012; Csiernik, Birnbaum, \& Decker Pierce, 2010; Freymond et al., 2014; Morgenshtern et al., 2011).

Two evaluations of research methods courses for social work students should be mentioned; these both used a measure of self-efficacy (an individual's assessment of their confidence in their ability to execute specific skills in a particular set of circumstances and thereby achieve a successful outcome) in a pre-post design at the start and end of the teaching. Unrau and Grinnell (2005) in the US reported that both BSW and MSW students' made statistically significant gains in research self-efficacy by the end of a semester (term) course. They observed that "students who started their research course with lower levels of self-efficacy made substantially greater gains in their research confidence compared to students who started out with higher levels of self-efficacy” (p. 639). Quinney and Parker (2010) in England focused on the outcomes of a course which combined knowledge and skills in research with the use of information and computer technology. Again, the evaluators reported statistically significant gains in self-efficacy. However, neither of these studies included an objective test of knowledge.

\section{A Pilot in Teaching Quantitative Methods in Social Work in the UK}

As part of the "Quantitative Methods Initiative," the ESRC, along with HEFCE and the British Academy, made funding available to 20 teaching groups across the UK to: (1) increase the number of social science graduates who are able to use quantitative research methods and statistical analyses (referred to together as “quantitative methods”); (2) facilitate quantitative methods curriculum development; (3) embed quantitative methods into the undergraduate timetable; and (4) expand the number and quality of quantitative methods lecturers in universities (MacInnes, 2015). One of the projects was for social work and was granted to a collaborative group involving five universities across England, Wales, and Northern Ireland. 
The project involved the development of an innovative, quantitative methods curriculum and resources to be delivered across the undergraduate social work curriculum. The curriculum was innovative in being designed specifically for social work students, taking into consideration the barriers and facilitators to teaching quantitative methods. In particular, the material was written to show the relevance of quantitative methods to understanding social problems and social work practice; it used social work practice and research examples, and included opportunities to practice applying the methods through activities of direct relevance to social work (see Table 1).

The curriculum consists of 10 individual lessons, referred to as teaching inputs, which are available on the accompanying website (https://www.beds.ac.uk/mswc) and are integrated into a textbook (see Author, year). Each teaching-input includes a PowerPoint presentation, which provides lecture slides to be presented in a classroom, comprehensive teaching notes to guide the lecturer as they go through each slide, and class activities to accompany the lecture material. Although there are PowerPoint presentations, lecture notes, and activities for each of the inputs, lecturers may wish to use all of just some of the inputs and they may modify the materials to best meet the needs of their class. The website includes the materials for the inputs, additional activities and online resources, and a short statistics course which are available to download and use. The teaching inputs and accompanying materials are designed to allow for flexible delivery to fit within existing structures and curriculums across social work programs. For example, the materials can be embedded across several modules (as described by University One below), or to be delivered sequentially in a discreet module (as described by University Two below). 
The quantitative method curriculum was evaluated across two universities to determine the extent to which the students' confidence and self-efficacy in using quantitative methods, and knowledge of quantitative methods changed after receiving the new curriculum. This evaluation aimed to test the following two hypotheses: (1) Students' self-efficacy in quantitative methods will increase; and (2) Students’ knowledge of quantitative methods will increase.

\section{Methods}

\section{Setting and Sample}

The materials were piloted and evaluated at two universities between 2012-2014 who delivered the materials in a way that best met their program and student learning needs. University One is a public university located in the Southwest of England offering a three-year undergraduate social work program with approximately 40 students in each year group. University One incorporated the first seven teaching inputs into an existing "Community Profiling” class in year one. The community profiling class involved social work students working in small groups (4-6 students) throughout the whole academic year to answer a research question identified by a community social service organization. Only the first seven teaching inputs were delivered as they provided students with the skills and knowledge necessary to carry out a research project that answered the organization's research question, which was not required to include data analysis beyond descriptive statistics. The delivery of the teaching inputs involved classroom lectures, small and large group exercises, and application of the material to the students' community profiling projects. The last three teaching inputs were incorporated into an existing "Child Welfare Policy, Practice, and Research" class in year two where the same social work students who completed the Community Profiling class in year one were tasked with demonstrating their understanding of quantitative research methods and statistical analyses by 
critiquing research articles that related to a specific child welfare topic, such as: "Do children in kinship care do better than children in foster care?” The delivery method of the three teaching inputs included classroom lectures, and small and large groups exercises and provided students with the skills and knowledge to critique quantitative research and statistical data analyses.

University Two is a public university located in Northern Ireland offering a three-year undergraduate social work program with approximately 70 students in each year group. University Two incorporated all 10 teaching inputs into an existing year two 12-week "Research for Policy and Practice” module. This class specifically focuses on research and covers quantitative and qualitative methods. The 10-teaching inputs were all delivered during the 12week course via classroom lecture and small and large group exercises. The students were assessed via a group presentation on the relevance of research to policy and practice and through an exam that assessed knowledge of research methods. Members of the research team and/or a colleague with experience in quantitative methods delivered the materials at both universities.

To evaluate the curriculum, a questionnaire aimed to assess confidence, self-efficacy, and knowledge of students was administered at two points in time: prior to the delivery of the quantitative curriculum, Time 1 (T1); and directly after its delivery, Time 2 (T2). The lead contact person, or their designee, at each university distributed either a paper questionnaire to the students at T1 and then at T2, or requested the students complete the questionnaire electronically through a password-protected online survey that could only be accessed by members of the research team. The paper questionnaires were sent to the researchers for data entry and analysis. Ethical approval was obtained from the Research Ethics Committee at the University of Bristol, which was the university responsible for conducting the evaluation. Students were informed that their participation in the study was voluntary and confidential and that their 
responses would not be shared with their lecturers nor would their participation or lack of participation impact on their grades. In order to maintain confidentiality, students were provided a simple personal identifier in order to match their T1 and T2 responses.

\section{Questionnaire Construction}

The author-constructed questionnaire assessed confidence and self-efficacy, knowledge, and demographics such as age, sex, past experience with math, and having a school-leaving qualification (e.g., taken and passed a class in high school) in math, statistics, psychology, or another science subject prior to entering university. Confidence and self-efficacy were included in the evaluation as previous research (Bolin et al., 2012; Freymond et al., 2014; Morgenshtern et al., 2011) found students’ confidence and self-efficacy in using research methods to increase when the material is directly relevant to their profession, and when students are able to apply the material to "real-life" like situations; two specific aspects of this quantitative method curriculum. Knowledge of quantitative methods was also included in the evaluation as knowledge does not appear to be a measured variable in previous research, and, more specifically, the knowledge questions used in this evaluation were developed based on the content of the material in the new quantitative method curriculum.

Confidence and self-efficacy. Two questions addressed how confident students felt working with numbers by asking them the following two questions: (1) Overall, how confident do you feel working with numbers in your daily life?; and (2) Overall, how confident do you feel working with numbers as a social work student (on placement and at university)? Possible responses were: not at all confident; not so confident; somewhat confident; confident; very confident (response categories were reduced from five to three for data analysis due to the small number of responses in certain categories [not confident; somewhat confident; confident]). The 
two confidence questions were analyzed independently to determine the percentage and frequency of students who were not confident, somewhat confident, and confident on the two separate questions at T1 and T2 and any differences in level of confidence on the two separate questions from $\mathrm{T} 1$ and $\mathrm{T} 2$.

Self-efficacy was assessed using seven statements modeled on Holden, Barker, Meenaghan and Rosenberg’s (1999) “research self-efficacy” scale. The scale itself was not used because the statements were not explicitly focused on confidence in applying knowledge and skills to social work and included statements that were not specific to quantitative methods. The revised scale developed consisted of topics that students were introduced to through the quantitative method curriculum via classroom lecture material or through small or large group exercises and activities. A “warm-up” item concerning the use of numbers in daily life (determining whether or not to change a mobile [cell] phone provider contract) preceded the seven statements. Following Holden et al.’s (1999) method, respondents were asked to rate their level of confidence for the "warm-up" item and each of the seven self-efficacy statements on a scale from 0-100 where $0=$ “cannot do at all;” 50 = “moderately certain can do;” and $100=$ “certainly can do.” Responses to the seven self-efficacy items in this study indicated satisfactory internal reliability for the scale pre-and post-test $(\alpha=80)$. However, because the aim was to assess self-efficacy in relation to elements of the curriculum rather than a "total score," the “warm-up” item and seven self-efficacy statements were analyzed independently. Measures of central tendency and standard deviations for each separate item at T1 and T2 and any differences in responses on each item from $\mathrm{T} 1$ to $\mathrm{T} 2$ were calculated.

Knowledge. Eight multiple-choice questions (MCQ) were constructed to assess students’ knowledge of basic statistics based on the material covered in the quantitative method 
curriculum. These addressed measures of central tendency, levels of measurement, probability sampling, independent and dependent variables, normal distribution, the purpose of inferential statistics, statistical significance, and causation or correlation. Example questions included: (1) The most frequently occurring number in a set of values is called the $\therefore$ (a) mean; (b) median; (c) mode; (d) range; and (2) A variable that is presumed to cause a change in another variable is called a(n): (a) categorical variable; (b) dependent variable; (c) independent variable; (d) intervening variable. The questions were not intended to form a scale, so the eight MCQs were analyzed separately to determine the percentage and frequency of students who answered each of the questions correctly at T1 and T2. Then, the total number of MCQs each student answered correctly was calculated as well as the measures of central tendency and standard deviation for total number of MCQs correct at T1 and T2, and any difference in total number of MCQs correctly answered from T1 to T2.

\section{Data analysis}

A total of 81 questionnaires matched from T1 and T2 were completed and included in the data analysis. Descriptive statistics were used to provide an overview of the sample's demographics and to compare respondents' confidence and self-efficacy and knowledge at T1 and T2. Chi-square test of independence was used to determine any statistically significant differences among the categorical variables measuring confidence and self-efficacy between T1 and T2. Due to non-normality of the data, Wilcoxon signed-rank tests were used to determine any statistically significant differences among the continuous variables measuring confidence and self-efficacy between T1 and T2, and to determine the statistical significance of any difference in total number of correct responses on the MCQ at T1 and T2. Alpha was set at .05.

\section{Findings}




\section{Sample Demographics}

Of the 81 undergraduate social work student respondents, 22 were studying at University One and 59 at University Two. Over 82\% $(n=67)$ of the respondents were female and 17.3\% $(n=14)$ were male. Their mean age was 27 years $(S D=6.6)$ with a range from 18 to 38 years. Nearly 31\% $(n=25)$ of respondents had a school-leaving qualification in Psychology, 27.2\% $(n=22)$ had a qualification in Science, 23.5\% $(n=19)$ had a qualification in Math, and 4.9\% $(n=4)$ had a qualification in Statistics.

\section{Confidence and Self-efficacy}

Table 2 reports the percentage and frequency of responses for level of confidence at T1 and $\mathrm{T} 2$ for the two confidence statements. While there was no statistically significant difference in respondents' reported confidence in dealing with numbers in their daily life at T2 when compared to $\mathrm{T} 1\left(\chi^{2}(2)=4.16, p=.13\right)$, there was a statistically significant improvement in their overall confidence with using numbers as a social work student at T2 when compared to T1 $\left(\chi^{2}(2)=18.49, p<.001\right)$. Table 2 also reports the mean, standard deviation, and median for the one “warm-up” item and seven self-efficacy statements. The respondents reported greater selfefficacy at T2 when compared to T1 across each of the seven numeric, quantitative, and statistical activities; with all these differences over time being statistically significant $(p<001)$.

-----Table 2-----

\section{Knowledge}

Table 3 reports the percentage and frequency of respondents who answered each knowledge question correctly at T1 and T2. Thirty-seven respondents had a higher number of questions correct at T2 than at T1, 32 respondents had a lower number of questions correct, and 12 respondents had the same number of questions correct at both time points. Across the eight 
knowledge questions, the median number of questions correct at $\mathrm{T} 1$ was $3(S D=1.4)$ with a range of $0-6$, and the median number of questions correct at $\mathrm{T} 2$ was $3(S D=1.45)$ with a range from 17; the difference from $\mathrm{T} 1$ to $\mathrm{T} 2$ was not statistically significant $(\mathrm{z}=-.85, p=.39)$.

-----Table 3-----

\section{Discussion and Implications for Social Work Education}

The findings from this study should be considered against several limitations. First, the generalizability is limited due to the small sample size and inclusion of students from only two universities. Second, the authors constructed the measurement of knowledge, which have not undergone psychometric testing. Third, although the same material was delivered at the two universities, one university incorporated the teaching inputs across two years and the other university incorporated the teaching inputs into one discreet class; therefore, it is also unknown whether one method of delivery is more effective than another. Although, it should be noted that the quantitative curriculum was designed to be flexible in terms of implementation to enable social work programs to incorporate them all at one time or across the whole social work degree. Despite such limitations, this study provides an indication as to how a specific quantitative method curriculum could be embedded in an undergraduate social work program, which has been found to increase confidence and self-efficacy among social work students.

One aim of social work education in the UK is to provide students with the knowledge and skills to become "research-minded" where, as future practitioners, they are able to critique and use research to inform their social work practice. This study evaluated the extent to which a newly developed 10-input quantitative method curriculum piloted at two universities in the UK enhanced students' confidence, self-efficacy in and knowledge of quantitative methods. The findings indicated that students' self-efficacy significantly increased from T1 to T2 across all 
seven self-efficacy statements. Students also reported feeling more confident in using numbers as a social work student, and felt more confident with numbers in daily life, although the latter was not statistically significant.

According to Bolin et al. (2012), self-efficacy varies among students and lecturers should, therefore, incorporate teaching methods that can cater to the different levels of knowledge and confidence of students. Bolin et al. (2012) argue for "social work instructors to start with what students already know about research as the basis for instruction and then move towards the challenge of learning that incorporates realistic, yet high, expectations” (p. 239). Such an approach is deemed to increase confidence and encourage students' learning. This study supports Bolin et al.'s (2012) claim as the quantitative method curriculum was developed to start with a basic discussion of numbers and why numbers matter in everyday life, which encouraged students to acknowledge that they participate in the research process on a regular basis. Starting with basic information and examples that students can relate to, such as the decision-making process in choosing a mobile phone provider, encourages students to see that research is something that is incorporated into their daily life; they are regularly participating in the research process and dealing with numbers. This may have enabled the students to feel comfortable and confident in moving through subsequent aspects of the quantitative method curriculum, thus, demonstrating higher levels of self-efficacy at T2.

This study also found that although the students as a whole did answer more questions correct at $\mathrm{T} 2$ when compared to $\mathrm{T} 1$, this difference was not statistically significant. The increase from T1 to T2 indicated only a very slight increase in knowledge with 37 students having a higher number correct at T2, 32 having a lower number correct at T2, and 12 students having the same number correct at T2. Such findings indicate that although students had a significant 
increase in confidence and self-efficacy, many students could not demonstrate this "perceived" knowledge and ability to make sense of statistics on a MCQ. A similar finding was found by Harrison, Lowery and Bailey (1991) among nursing students where attitudes towards research improved from pre- to post-test, yet their knowledge of research remained unchanged.

When examining the questions that students correctly answered at T1 and T2, there appears to be an increase in knowledge in terms of measures of central tendency, identifying an independent variable, and sampling. Therefore, when implementing the 10 -input quantitative method curriculum in the future, social work educators may want to give equal or more attention to other aspects of quantitative methods, such as alpha level and $p$-value, meaning of inferential statistics, standard deviation, and causation and correlation (spurious relationship), as well as opportunities to practice engaging with such material. As mentioned in the limitations section, the MCQ was developed by the researchers and was not subjected to psychometric testing. Therefore, the wording of the questions could have caused some confusion for the students. For example, more students answered the following question incorrectly at T2 than at T1: "When $p<.05$ is reported in a journal article that you read for an observed relationship, it means that: ...”. The correct answer was the selection of two correct responses that addressed both statistical significance (assuming the author used an alpha level of .05) AND rejecting the null hypothesis. Could the students have viewed this as a trick question or selected only one of the two correct responses, thus answering the question incorrectly?

Yet, another explanation for the lack of greater knowledge from T1 to T2 could be based on the extent to which the students practiced or actively engaged with the more complex statistical concepts. The students at University One were required to carry out a research project in year one, yet only needed to incorporate the use of descriptive statistics in their research; 
concepts where students demonstrated increased knowledge. In year two, they were required to assess a piece of research, which would require them to engage in more complex statistical concepts (e.g., $p$-value; inferential statistics; spurious relationships), but not conduct the research themselves. Students at University Two were assessed via a group presentation on the relevance of research to policy and practice and through an exam that assessed knowledge of research methods. Teaching and learning theory suggests there are five factors that underpin successful learning (i.e. wanting; needing; doing; obtaining feedback; digesting the feedback) (Race, 2015). According to this theory, students learn best by doing and then obtaining feedback on the doing. Therefore, the lack of demonstrated knowledge on more complex research and statistical concepts could be explained by the fact that the students did not have to complete assignments or produce a product where they actively completed the statistical tasks themselves. The students in this study were open to learning through their increased confidence and self-efficacy, yet were not given the opportunity to demonstrate the knowledge through formal assessments.

Future teaching of quantitative methods should consider the incorporation of online activities, experiential learning, homework assignments, and formal assessments that can encourage students to move at their own pace and practice applying the material to real-life like situations. Such practice opportunities can potentially enhance self-efficacy and confidence as well as knowledge. Additionally, making connections with social work practice and combining activities or links to field placements could demonstrate how research is used in practice and provide opportunities for students to practice applying (i.e. “doing”) the material (Einbinder, 2014; Freymond at al. 2014; Morgenshtern et al., 2011). Finally, this study points to the need for continual evaluations of research methods teaching including new and creative ways to evaluate 
the outcomes of research teaching that incorporates qualitative and quantitative methods in order to test knowledge.

\section{References}

Author. (year).

Author. (year).

Barnett, S. \& Ceci, S. (2002). When and where do we apply what we learn?: A taxonomy for far transfer. Psychological Bulletin, 1286, 612-637.

Bell, L., \& Clancey, C. (2013). Postgraduate students learning about research: Exploring the attitudes of social work and mental health students in an English university setting. Social Work \& Social Sciences Review, 16(2), 37-50.

Bolin, B.L., Lee, K.H., GlenMaye, L.F., \& Yoon, D.P. (2012). Impact of research orientation on attitudes toward research of social work students. Journal of Social Work Education, 48(2), 223-243.

Bywaters, P. (2008). Research strategy for social work in the UK. British Journal of Social Work, 38(5), 936-952.

Calderwood, K. (2002). Incorporating multiple epistemologies into teaching statistics to social work students. Journal of Teaching in Social Work, 22, 17-32.

Csiernik, R., Birnbaum, R., \& Decker Pierce, B. (2010). Practising social work research: Case studies for learning. Toronto: University of Toronto Press.

Daniel, F. \& Braasch, J., (2013). Application exercises improve transfer of statistical knowledge in real-world situations. Teaching of Psychology, 403, 200-207.

Economic and Social Research Council (ESRC). (2015). Undergraduate activities. Retrieved 
from: http://www.esrc.ac.uk/research/skills-training-development/qmi/undergradactivities.aspx.

Einbinder, S.D. (2014). Reducing research anxiety among MSW students. Journal of Teaching in Social Work, 34(2), 2-16.

Elliott, W., Choi, E., \& Friedline, T. (2013). Online statistics labs in MSW research methods courses: Reducing reluctance toward statistics. Journal of Social Work Education, 49, 8195.

Epstein, I. (1987) Pedagogy of the perturbed: Teaching research to the reluctants, Journal of Teaching in Social Work, 1, 71-89

Freymond, N., Morgenshtern, M., Duffie, M., Hong, L., Bugeja-Freitas, S., \& Eulenberg, J. (2014). Mapping MSW research training. Journal of Teaching in Social Work, 34, 248268.

Gibbs, A., \& Stirling, B. (2010). Reflections on designing and teaching a social work course for distance and on-campus students. Social Work Education, 29(4), 441-449.

Gibbs, A., \& Stirling, B. (2013). 'It’s about people and their environment': Student social workers’ definitions of social work research. Social Work Education, 32(3), 317-330.

Gordon, S. (2004). Understanding students' experiences of statistics in a service course. Statistics Education Research Journal, 31, 40-59.

Green, R., Bretzin, A., Leininger, C., \& Stauffer, R. (2001). Research learning attributes of graduate students in social work, psychology, and business. Journal of Social Work Education, 37(2), 333-341.

Harrison, C., \& Humphreys, C. (1998). Keeping research in mind: Final report and 
recommendations for future developments in social work education and training. Central Council for Education and Training in Social Work (CCETSW).

Harrison, L., Lowery, B., \& Bailey, P. (1991). Changes in nursing students’ knowledge about the attitudes toward research following an undergraduate research course. Journal of Advanced Nursing, 16(7), 807-812.

Holden, G., Barker, K., Meenaghan, T., \& Rosenberg, G. (1999). Research self-efficacy: a new possibility for educational outcome assessment. Journal of Social Work Education, 35, $463-476$.

Joint University Council Social Work Education Committee (JUC SWEC). (2006). A social work research strategy in higher education, 2006-2020. Retrieved from: http://www.swap.ac.uk/docs/strategy_JUCSWEC.pdf.

MacInnes, J. (2015). Quantitative methods strategic advisor report. Retrived from: http://www.esrc.ac.uk/files/research/qmi/quantitative-methods-strategic-advisor-report/.

MacIntyre, G., \& Paul, S. (2013). Teaching research in social work: Capacity and challenge. British Journal of Social Work, 43, 685-702.

Macke, C., \& Tapp, K. (2012). Teaching research to MSW students: Effectiveness of the teambased learning pedagogy. Journal of Teaching in Social Work, 32, 148-160.

McCrystal, P., \& Wilson, G. (2009). Research training and professional social work education: Developing research-minded practice. Social Work Education, 28(8), 856-872.

Morgenshtern, M., Freymond, N., Agyapong, S., \& Greeson, C. (2011). Graduate social work students’ attitudes toward research: Problems and prospects. Journal of Teaching in Social Work, 31, 552-568.

Orme, J., \& Powell, J. (2008). Building research capacity in social work: Process and Issues. 
British Journal of Social Work, 38(5), 988-1008.

Orme, J., Sharland, E.R., Manthorpe, J., Fook, J., \& Powell, J. (2008). An audit of baseline resources for social work research. Retrieved August 28, 2015 from: http://www.esrc.ac.uk/_images/Social_work_audit_report_tcm8-13305.pdf.

Powell, J., \& Orme, J. (2011). Increasing the confidence and competence of social work researchers: What works? British Journal of Social Work, 41, 1566-1585.

Quality Assurance Agency (QAA) for Higher Education. (2008). Subject benchmark statement: Social Work. Retrieved from: http://www.qaa.ac.uk/en/Publications/Documents/Subjectbenchmark-statement-Social-work.pdf.

Quinney, A. \& Parker, J. (2010). Developing self-efficacy in research skills: Becoming research minded. In H. Burgess and J. Carpenter (eds.) The outcomes of social work education: Developing Evaluation Methods. Monograph 2. Southampton, the Higher Education Academy.

Race, P. (2015). The lecturer's toolkit: A practical guide to assessment, learning, and teaching (4 $4^{\text {th }}$ ed.). Abingdon: Routledge.

Ramirez, C., Schau, C., \& Emmioglu, E. (2012). The importance of attitudes in statistics education. Statistics Education Research Journal, 112, 57-71.

Secret, M., Ford, J., \& Rompf, E. (2003). Undergraduate research courses: A closer look reveals complex social work student attitudes. Journal of Social Work Education, 393, 411-422.

Sharland, E. (2009). Main report to the Economic and Social Research Council Training and Development Board. Retrieved from: http://www.esrc.ac.uk/_images/Main_report_SW_and_SC_tcm8-4647.pdf.

Unrau, Y., Richard M., \& Grinnell, R. (2005). The impact of social work research courses on 
research self-efficacy for social work students. Social Work Education, 24,(6), 639-651. 
Table 1: Quantitative Method Curriculum: 10 Teaching Inputs

Learning Outcomes

Examples Used

\section{Why numbers matter in everyday life}

\section{Why numbers matter in social work}

\section{Research designs: Who is being studied?}

\section{Research designs: What are the issues being studied?}

* Describe how numbers are a critical component of everyday life

* Explain how numbers can be created, represented and interpreted in social life

* Explore how quantification of an issue can help us understand a complex issue

* Identify some basic statistical concepts

* Describe how number are a critical component of social work practice

* Explain how numbers can be created, represented and interpreted in social work practice

* Explore how quantification of an issue can help us understand a complex issue

* Identify concepts of incidence, prevalence and comparison

* Define 'sample' and identify different types of samples

* Describe how different samples can influence the research findings

* Explain the importance of response rates

* Apply issues of sample bias in research to antidiscriminatory practice issues and stereotyping in social work practice and policy

* Define 'variable' and identify different types of variables used in quantitative research

* Explain reliability and validity

* Define and explain a standardized instrument

* Reflect on implications for social work practice
* Selecting a mobile phone

* Shopping at a supermarket

* Hate crimes

* Population change/migration

* Educational outcomes and ethnicity

* Demographics of children in UK

* Domestic abuse

* British Crime Survey

* Domestic abuse and child abuse

* Treatment for male perpetrators

* Alcohol use and misuse

* Parental alcohol misuse and parenting

* Children in care

* Violence and mental illness
* Children in care (revisited)

* General Health Questionnaire (GHQ) and social workers

* Strengths and Difficulties Questionnaire (SDQ) and children 


\section{Research designs: Is there a problem? Can social work help?}

6. Research designs: What works?

\section{Working with numbers: Descriptive statistic}

\section{Working with numbers: An}

introduction to probability and significance
* Identify routine information gathered by agencies and describe the strengths and limitations to its use for research purposes

* Identify existing large-scale datasets and describe how they can be used for research

* Explain the contribution of questionnaires to research and identify aspects of questionnaire design

* Describe repeated measures and explain how this approach to data collection can improve understanding of social issues

* Identify and explain three designs of evaluation: before and after studies; quasi-experimental designs; experimental designs

* Provide a rationale for the use of each of the three designs and describe the strengths and limitations to each

* Identify and defined levels of measurement and measures of central tendency

* Calculate frequency, percentage, range, measures of central tendency and be able to critique and justify their use for the exercise problems

* Describe situations in which different levels of measurement and measure of central tendency are useful and appropriate

* Define and discuss the theory and rules of probability

* Calculate probability and create a probability distribution

* Describe the characteristics of a normal curve and interpret a normal curve using example data
* Children and adoption

* Alcohol use and older people

* Anti-social behaviour and drink driving

* Treatment of alcohol misuse

* Receipt of attendance allowance
* Newly qualified social workers entering children services

* Crisis intervention model to prevent care

* Evaluation of task-centred social work

* Reablement service for adults

* Assessment scores of students
* Assessing level of need for services

* Reablement services (revisited)

* Social work salaries 


\section{Working with numbers: \\ Comparison of means}

10. Working with numbers:

Correlation and causation
* Define research question, research hypothesis, null hypothesis and statistically significant

* Discuss the basic requirements for testing the difference between two means

* Define and describe the difference between alpha level, p value and Type I and Type II errors

* Describe how multiple variables may interact with one another

* Explain the role of intervening variables

* Identify how interpretation of statistics may be affected by outliers and misinterpretations
* Singing and mental health in adults

* Hope and social work students

* Kinship care versus non-kinship care

* Sexual violence and public awareness campaigns

* Posttraumatic stress disorder (PTSD) and Cognitive Behavioural Therapy 
Table 2: Self-Reported Confidence/Self-Efficacy at T1 and T2

\begin{tabular}{|c|c|c|c|c|c|c|}
\hline Question (Confidence) & \multicolumn{2}{|r|}{$\begin{array}{l}\text { T1 } \\
\%(f)\end{array}$} & \multicolumn{2}{|l|}{$\begin{array}{l}\mathrm{T} 2 \\
\%(f)\end{array}$} & & \\
\hline \multicolumn{7}{|l|}{ Using numbers in daily life } \\
\hline Not confident & & $20.3 \%(16)$ & \multicolumn{2}{|c|}{$12.5 \%(10)$} & & \\
\hline Somewhat confident & & $36.7 \%(29)$ & \multicolumn{2}{|c|}{$28.8 \%(23)$} & & \\
\hline Confident & & $43 \%(34)$ & \multicolumn{2}{|c|}{$58.8 \%(47)$} & & \\
\hline \multicolumn{7}{|l|}{ As a social work student } \\
\hline Not confident & & $51.9 \%(40)$ & \multirow{3}{*}{\multicolumn{2}{|c|}{$\begin{array}{l}22.8 \%(18) \\
41.8 \%(33) \\
35.4 \%(28)\end{array}$}} & & \\
\hline Somewhat confident & & $36.4 \%(28)$ & & & & \\
\hline Confident & & $11.1 \%(9)$ & & & & \\
\hline \multirow[t]{2}{*}{ Activity (Self-Efficacy) } & \multicolumn{2}{|r|}{ Time 1} & \multicolumn{2}{|r|}{ Time 2} & \multirow[b]{2}{*}{$\mathbf{z}$} & \multirow[b]{2}{*}{$p$} \\
\hline & $M$ & (SD) Mdn & $M$ & (SD) Mdn & & \\
\hline Change mobile phone provider & 74.32 & $(23.29) 80$ & 79.64 & $(21.33) 80$ & -2.44 & .02 \\
\hline \multicolumn{7}{|l|}{ Chose appropriate measure of } \\
\hline \multicolumn{7}{|l|}{ Evaluate the quality of quantitative } \\
\hline research & 42.16 & $(23.64) 50$ & 67.35 & $(18.46) 70$ & -6.47 & $<.001$ \\
\hline Explain statistical significance & 41.92 & $(28.06) 50$ & 65.6 & $(23.59) 70$ & -5.96 & $<.001$ \\
\hline Select and present quantitative data & 53.65 & (26.9) 50 & 70.62 & (20.64) 70 & -4.39 & $<.001$ \\
\hline Explain validity and reliability & 43.91 & $(27.61) 50$ & 72.54 & $(22.42) 75$ & -5.91 & $<.001$ \\
\hline \multicolumn{7}{|l|}{ Compare the quantitative findings of } \\
\hline Know which statistical test to use & 23.21 & $(25.53) 20$ & 49.56 & $(24.7) 50$ & -5.84 & $<.001$ \\
\hline
\end{tabular}


Table 3: Knowledge of Quantitative Methods: Correct Responses at T1 and T2

\begin{tabular}{lll}
\hline Topic & $\begin{array}{l}\mathbf{T 1} \\
\mathbf{\%}(\boldsymbol{f})\end{array}$ & $\begin{array}{l}\mathbf{T 2} \\
\mathbf{\%}(\boldsymbol{f})\end{array}$ \\
\hline$p<.05$ & $19.8 \%(16)$ & $3.7 \%(3)$ \\
Inferential statistics & $34.6 \%(28)$ & $32.1 \%(26)$ \\
Standard deviation & $28.4 \%(23)$ & $28.4 \%(23)$ \\
Ordinal & $35.8 \%(29)$ & $46.9 \%(38)$ \\
Independent variable & $19.8 \%(16)$ & $27.2 \%(22)$ \\
Spurious relationship & $35.8 \%(29)$ & $24.7 \%(20)$ \\
Mode & $66.7 \%(54)$ & $81.5 \%(66)$ \\
Random sample & $51.9 \%(42)$ & $67.9 \%(55)$ \\
\hline
\end{tabular}

